\title{
電気生理学的アプローチによる喉頭基礎研究
}

\author{
杉 山 庸一郎
}

\section{An Electrophysiological Approach to Basic Laryngology}

\begin{abstract}
Yoichiro Sugiyama
Laryngeal movements including breathing, phonation, and airway protective reflexes, such as swallowing and coughing, are mainly controlled by the neuronal networks in the brain stem. To understand the mechanisms underlying these movements, the morphological and functional properties of the brain stem neurons that participate in the production of these movements should be investigated. We previously examined the functional roles of the brain stem neurons that contribute to the generation of laryngeal movements using electrophysiological and morphological procedures. The findings of two studies are introduced in the presentation. In the first study, we reported the projections of the swallow-related neurons in the swallowing central pattern generator in the medulla oblongata using a tracer injection in anesthetized paralyzed guinea pigs. This study indicated that the swallowrelated neurons were broadly distributed in the nucleus tractus solitarius and reticular formation, and that there appeared to be complex interconnections amongst the nucleus tractus solitarius, the reticular formation, and the cranial motor nuclei. The other study showed that the activity of the respiratory neurons in the ventrolateral medulla, in particular between the Bötzinger complex and the rostral ventral respiratory group, was altered during fictive vocalization, swallowing, and coughing in a type-specific manner, and thus supported the hypothesis that the medullary respiratory neurons are multifunctional and that the respiratory center in the network circuitry underlying these behaviors can be shared.
\end{abstract}

Key words : laryngology, electrophysiology, vocalization, swallowing

\section{は じめに}

喉頭は耳鼻咽㑨科領域において, 最もメカニカルな器官 の一つである。安静呼吸時は呼吸関連運動を行っている声 帯が，嚥下，咳などの気道防御反射時，あるいは発声時に 急激にその活動パターンを変化させ，それぞれの振る舞い に適した運動を行う. 従って, 喉頭科学の研究を行う上で, この動的に「動く」喉頭の制御機構を解明することは非常 に重要である，そして，喉頭運動制御メカニズムを解析す るために, 生理学, 特に電気生理学は合目的である, 我々 はこれまで, 電気生理学的研究手法を主に用いて喉頭科学 の基礎研究を行ってきた，本稿は我々の研究を理解するた めの基礎的な知識と, これまで行ってきた研究内容の一部 を示すものである.

\section{電気生理学研究の基礎}

活動電位とその記録 (ニューロン, 神経，筋肉)

運動ニューロン（Motoneuron）へ投射するPremotor neuronのシナプス前終末から放出された神経伝達物質に より運動ニューロン細胞内にシナプス後電位が発生する. そして, ニューロンの膜電位が闇值を超えると活動電位が 発生する。神経細胞で発生した活動電位は減衰することな
く軸索に沿って伝播し，支配筋の終板へ向かう。運動神経 は終板に近づくとミエリン鞘を失いシナプス前終末を形成 する．活動電位が終板に到達するとアセチルコリンが放出 され，神経筋接合部を介して筋線維の膜に活動電位を発生 させる。このようにPremotor neuronからの制御を受けた Motoneuronは支配筋を駆動するのである，ある運動を観 察する場合, その筋活動を記録することが重要であるが, その場合は筋肉に発生するこの活動電位を記録する筋電図 が使用される，実験系によっては筋活動を筋弛緩郕で抑制 した上で運動を記録する必要もあり，その場合は軸索を伝 播する活動電位を記録する神経電図が用いられる。また, 運動を制御するニューロンの活動自体を解析する場合, ニューロンに発生した活動電位を細胞外で記録する方法 (細胞外記録) と細胞内に電極を刺入し, 膜電位を計測す る方法 (細胞内記録) が用いられる。筋活動あるいは神経 活動を複数同時に記録することで, 様々な複雑な運動の記 録や解析を行うことが出来る。ニューロン活動については 個々のニューロンの活動パターンを解析するだけでなく, その入力様式や接続を解析することで，それぞれのニュー ロンのネットワーク内での役割を類推することが出来る. 本稿で主に使用されている細胞外記録ではその中でも活動 パターンの解析を主に行っている.

京都府立医科大学耳鼻咽喉科・頭頸部外科学教室

Department of Otolaryngology-Head and Neck Surgery, Kyoto Prefectural University of Medicine 
呼吸性，非呼吸性運動とその誘発

1 , 呼吸

呼吸運動は横隔膜，外肋間筋などの吸気筋収縮による吸 息とそれに引き続く腹直筋や腹斜筋などの呼気筋収縮によ る呼息で構成されている。これらの筋肉は呼吸筋とも呼ば れているが，咽頭や喉頭を動かす筋肉も安静呼吸時は呼吸 関連運動を行う。例えば咽頭筋の多くは呼気性活動を示す し, 声帯内転筋は呼気性に外転筋は吸気性に活動してい る。このように咽頭喉頭も安静呼吸時は呼吸中枢による制 御を受けている。呼吸時声帯運動については，声帯内転筋 である甲状披裂筋は呼気早期に収縮し，肺の虚脱を防いで いる。 また, 後輪状披裂筋や輪状甲状筋は吸気時に活動し, 吸気時の声門腔を保っている。このような呼吸性喉頭運動 を制御する呼吸中枢は脳幹に存在している ${ }^{1)}$ 。延䯣には孤 束核の腹外側に背側呼吸ニューロン群 (Dorsal respiratory group）が，延髄腹外側には尾側腹側呼吸ニューロン群 (caudal ventral respiratory group, cVRG), 吻側腹側呼吸 ニューロン群 (rostral ventral respiratory group, rVRG), pre Bötzinger complex (pre BötC), Bötzinger complex (BötC), Retrotrapezoid nucleus/parafacial respiratory groupが存在している ${ }^{2)}$. また, 橋背外側領域には橋呼吸 ニューロン群 (Pontine respiratory group, PRG) と呼ばれ るニューロン群が存在している ${ }^{2)} . \mathrm{cVRG}, \mathrm{BötC} に は$ 喉頭 運動ニューロンに投射するニューロンが存在し，PRG も声 帯内転筋の呼気性活動を制御しているといわれており ${ }^{3)}$, 喉頭運動制御に関与している。このように, 呼吸時声帯運 動は呼吸中枢の様々な領域からの制御を受けている.

2 , 発声

発声運動も脳幹の制御を受けている。発声の制御経路に ついてはAnterior cingulate cortexから Midbrain periaqueductal gray（PAG）を経由して後疑核 (Nucleus retroambiguus, NRA) へ投射し，そこから疑核 (Nucleus ambiguus, NA）に存在する運動ニューロンへ投射する経路, また，Motor cortexから網様体を経由してNAに向かう経 路が存在している ${ }^{4)}$. PAGは発声のいわゆる gateの役割 を担って扔り，PAGへの電気刺激あるいは化学刺激によ り発声が誘発される ${ }^{4)}$. 発声時声帯は内転, 伸長し, 強い 呼気に伴って声帯粘膜波動が生じることで喉頭原音が生成 される。この時, 甲状披裂筋および輪状甲状筋の強い収縮 が見られ，特に呼吸時に吸気優位で活動する輪状甲状筋が 呼気優位にシフトするのが発声の特徵とされている. 発声 運動は音声と同時に上記筋の特徴的な活動パターンとして 記録される ${ }^{5)}$.

3 , 嚥下

嚥下は口腔期，咽頭期，食道期に分類されるが，咽頭期 嚥下は特に再現性の高いパターン化された不随意運動と考 えられている ${ }^{6,7)}$. 咽頭期嚥下時は顎舌骨筋，オトガイ舌 骨筋の収縮に続き, 咽頭収縮筋の連続的な収縮と甲状舌骨 筋収縮が起きる。さらに声門閉鎖が起こり，輪状咽頭筋の 弛緩により食塊が食道に運ばれる ${ }^{8)}$ 。これらの運動は主に
舌下神経，迷走神経咽頭枝，反回神経などにより制御され ており,この一連のパターン生成は主に延髄で行われてい $る^{7 \sim 9)}$. 咽頭期嚥下の確認は咽頭収縮筋, 甲状舌骨筋, 甲 状披裂筋の嚥下関連活動などが指標として用いられる。咽 頭期嚥下は食塊の咽頭への流入による感覚情報が, 上喉頭 神経内枝や舌咽神経を介して孤束核に伝えられることで生 じる，従って上喉頭神経内枝を電気刺激することで咽頭期 嚥下を誘発することが出来る ${ }^{6,7)}$.

4 , 咳

咳は喉頭あるいは気管が刺激された時，異物排出のため に行われる気道防御反射の一つであり，主に脳幹に存在す る神経ネットワークにより生成および制御されている ${ }^{10)}$. 橋の呼吸中枢も咳制御に貢献しているが ${ }^{11)}$ ，特に延髄に存 在する呼吸ニューロン群による制御は重要である ${ }^{9,12,13)}$. 咳運動は大きな吸気とそれに引き続く一時的な声門閉鎖と その後の爆発的な呼気により構成されており，それぞれ咳 におけるinspiratory phase, compressive phase, expulsive phase と呼ばれている ${ }^{14)}$ 。また，咳運動は気管への刺激や 上喉頭神経内枝, 反回神経を電気刺激することで誘発さ れ, 横隔膜, 甲状披裂筋, 腹筋の特徵的な活動パターンと して記録される。

\section{喉頭科学における電気生理学研究}

\section{喉頭の多機能性とセントラルパターンジェネレーター}

通常喉頭は呼吸性活動を示すが，様々な入力により他の 振る舞いへシフトするため, 喉頭は多機能性を有すると言 われている。これは，喉頭が呼吸だけでなく嚥下，咳，く しゃみなどの気道防御反射機能を担い，また進化の過程で 発声を獲得したことにより, 多彩な運動を行うことからも わかる。この多機能性は主に脳幹に存在するセントラルパ ターンジェネレーター (Central pattern generator, CPG) で制御されている. CPG とは, 運動を誘発する入力系から 運動パターン生成を行い, そしてその運動を駆動する運動 ニューロン群をすべて含む，神経ネットワークのことであ る。嚥下，咳，発声にはそれぞれのCPGがその生成や制 御に重要な役割を担っており,このCPGが呼吸中に駆動 されることで，喉頭は呼吸性運動から他の振る舞いに変化 するのである。

\section{Fictive models}

脳幹の神経ネットワークを解析するためにはニューロン の活動記録が必要である。実際我々がニューロン活動を記 録する場合に, 細胞外記録であれ細胞内記録であれ微小ガ ラス電極やタングステン電極などの細い電極を脳幹に刺入 し，小さいものでは径 $10 \mu \mathrm{m}$ ほどのニューロンの活動を記 録しなければならない，従って発声や嚥下，咳などの反射 により脳が動いてしまうと安定して記録し続けることが困 難となる。そのため筋弛緩剂で筋活動を停止させ, 安定し た記録を可能にしている。この場合，様々な振る舞いを筋 活動で確認出来ないため, 神経活動パターンをもとに仮想 


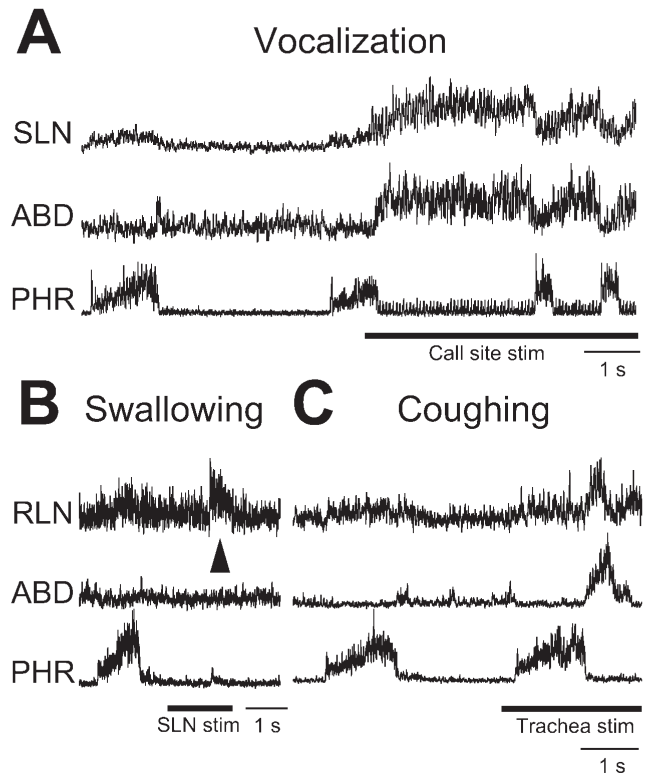

図 1 麻酔下非動化モルモットにおける発声 $(\mathrm{A})$, 燕下 $(\mathrm{B})$, 咳時 $(\mathrm{C})$ の神経活動。 $\mathrm{ABD}$, 腹 筋神経; Call site stim, 脳幹発声経路電気刺 激; PHR, 横隔神経; RLN, 反回神経; SLN, 上喉頭神経; Trachea stim, 気管刺激. (Sugiyama et al. 2014. Figure 1 より抜粋)
化する必要がある。これがFictive modelである，例えば Fictive vocalizationであれば本来発声時には短い吸気の後 に輪状甲状筋，腹筋の強い収縮と音声が観察されるが, 筋弛緩によりそれらの確認が不可能になるため, それに 代わって中脳中心死白質を電気刺激している状態で短い 横隔神経活動と強い上喉頭神経外枝, 腹筋神経活動が起 こった場合に発声したと定義するのである ${ }^{5)}$ 。この方法 を用いて, 我々は脳幹のニューロン活動を記録しながら 発声, 嚥下, 咳などの様々な運動時のニューロンの活動 変化やその投射経路の解析などを行っている。（図 1)

\section{研 究 結 果}

\section{嚥下関連ニューロンの投射経路}

我々はこれまで舆下CPGの解明を目的とした研究を 行ってきた。その中で, この研究は嚥下 $\mathrm{CPG}$ を構成する 神経ネットワークの一部を示したものである。與下 $\mathrm{CPG}$ は喉頭感覚入力を受ける孤束核のニューロンからパター ンを生成し, そして実際に筋活動を駆動する運動ニュー ロンまでを含む神経ネットワークのことだが，その内， いわゆるSensory-relay neurons (Type 1 swallowing-related neurons (SRNs)) や運動ニューロン (Type 3 SRNs) はそれぞれ燕下惹起のための感覚入力, 與慗下運動駆動の ための運動出力機能を有しているが, 複雑な嚥下運動を
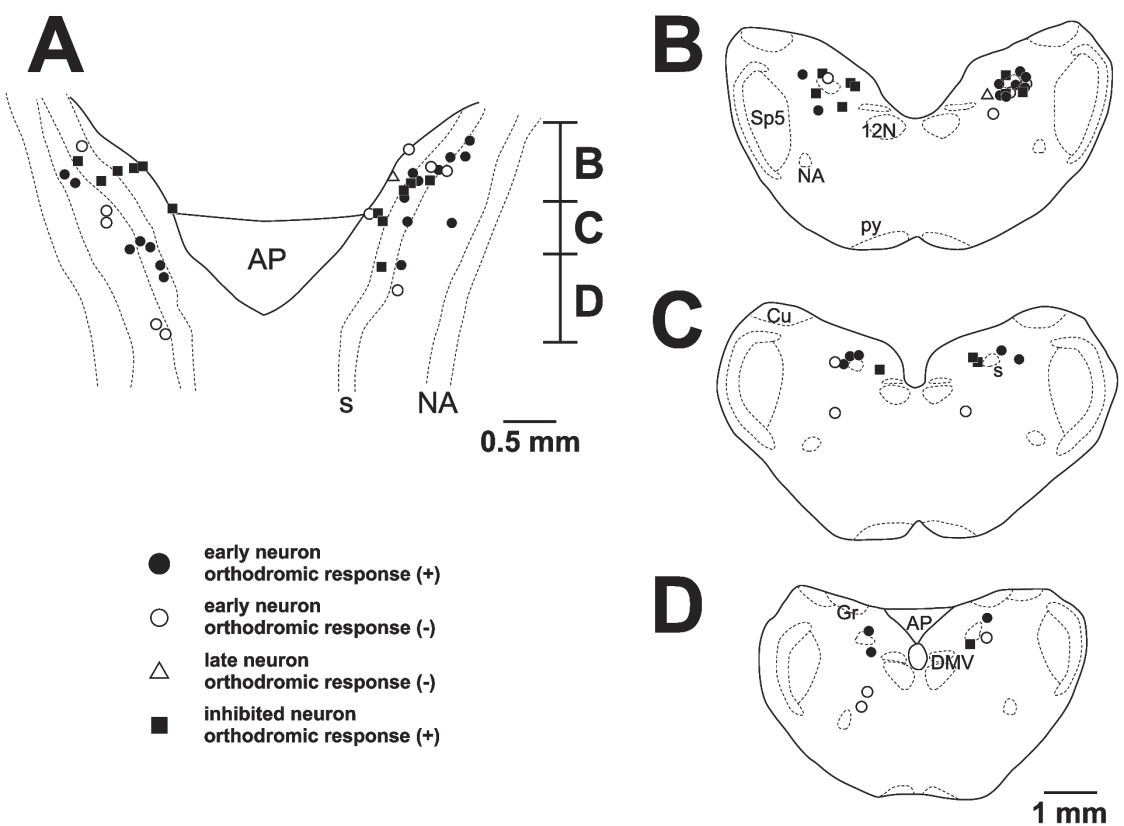

図 2 嚥下関連ニューロンの局在. A は冠状断切片, B-D は水平断切片での再構成を示して いる。 丸と三角は嚥下時に発火する嚥下関連ニューロン，そのうち黒は上喉頭神経か

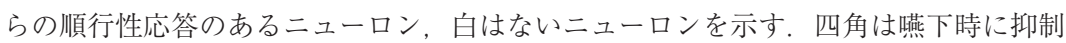
される嚥下関連ニューロンを示す。 AP, 最後野; Cu, 楔状核 $; \mathrm{DMV}$, 迷走神経背側運 動核; Gr, 薄束核; NA, 疑核; s, 孤束; Sp 5, 三叉神経脊髄路核； py, 錘体路； $12 \mathrm{~N}$, 舌 下神経核. (Sugiyama et al. 2011. Figure 2 より抜粋) 
制御したり，左右の動きを同期するパターン生成機構は基 本的には有していない ${ }^{6)}$ 。このパターン生成は主にinterneuronsであるType 2 SRNsで行われていると考えら れる ${ }^{6)}$.この Type 2 SRNsには上喉頭神経からの多シナプ ス性順行性入力を受けるニューロンも存在するため, 上喉 頭神経電気刺激による検索とその活動性の解析はこれまで も行われてきた ${ }^{6,15)}$ 。また, Type 3 SRNsである喉頭運動 ニューロンやそのPremotor neurons（これはType 2 SRNsに該当する）の與下時活動解析も行われてきた ${ }^{16,17)}$. しかしながら Type 2 SRNsの投射経路については, これ までほとんど報告が見られていない，そこで我々はこの Type 2 SRNs の活動解析と投射経路について, 神経トレー サーをSRNに注入する方法を用いて解析を行った ${ }^{7}$ 。麻酔 下非動化モルモットを用い，嚥下をモニターするために反 回神経, 迷走神経咽頭枝, 舌下神経甲状舌骨筋枝の活動を 記録し，上喉頭神経電気刺激により嚥下を誘発した。延䯣 の孤束核周囲から網様体にかけてのニューロンを検索し, 嚥下時に活動が変化するニューロン，つまりSRNを確認， その後トレーサーを注入して投射経路を検討した. SRNs は孤束核周囲から網様体にかけて広く存在しており（図 2 ), 孤束核内の連絡, 孤束核と網様体間での連絡, 網様体 から対側への投射，孤束核や網様体から疑核への投射など が明らかとなった（図 3 )。この結果により，これまで提唱

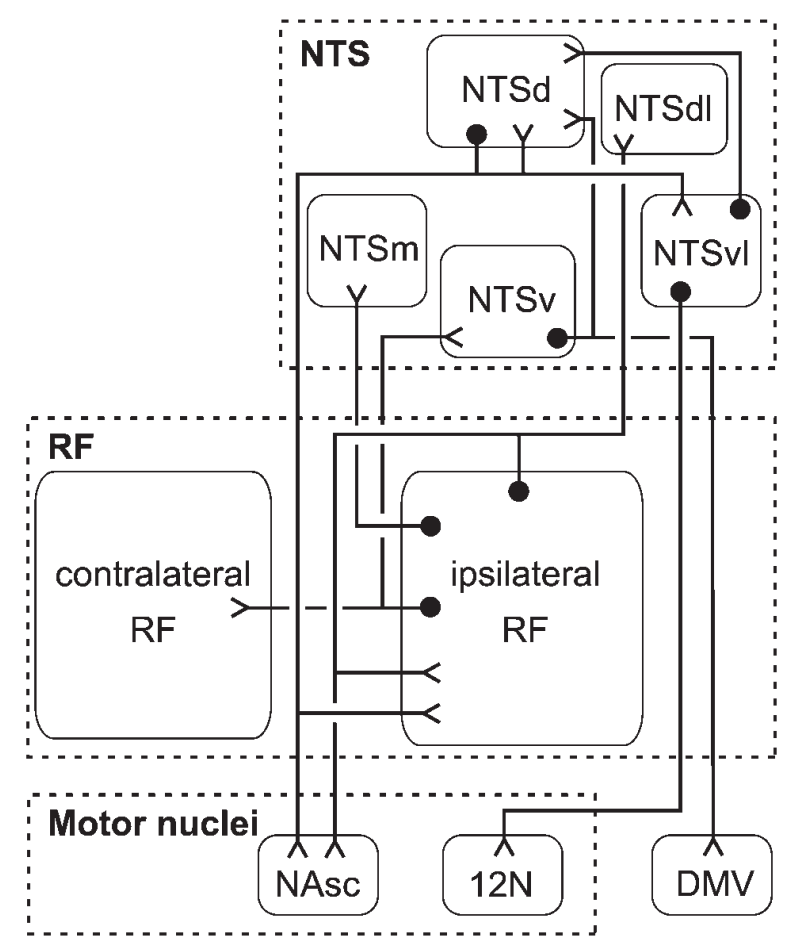

図 3 嚥下関連ニューロンネットワークのシェーマを示す. $\mathrm{NTS}$, 孤束核 (d, 背側覀核; $\mathrm{dl}$, 背外側亜核 ; m, 内側 亜核; v, 腹側亜核; $\mathrm{vl}$, 腹外側亜核); NAsc, 疑核 (semicompact formation); RF, 網様体. (Sugiyama et al. 2011. Figure 12 より抜粋)
されていた孤束核近傍のDorsal swallowing group と疑核 近傍のVentral swallowing groupによる嚥下生成機構 $p^{8)}$, 孤束核から疑核への直接投射による制御仮説 ${ }^{18)}$ は 嚥下 $\mathrm{CPG}$ のすべてを反映しているのではなく，より複雑 なネットワークが存在することが明らかになった

\section{延髄腹側呼吸ニューロン群の発声, 嬩下, 咳時活動}

喉頭運動ニューロンやそのPremotor neurons は多機能 性を有し呼吸, 発声, 嚥下, 咳などの呼吸性, 非呼吸性運 動生成に貢献しているが ${ }^{16,17)}$ ，それ以外のニューロンも これらの運動生成に関与している可能性がある。 上述にも あるように，安静呼吸時に呼吸性運動を行っていた喉頭や その他の呼吸筋がその運動パターンを劇的に変化させ，そ の他の非呼吸性運動へ移行するためには多くの神経ネット ワーク構成を変化させる必要があり，その一つに呼吸中枢 の変化があると考えられる。そこで我々はrVRGから BötC のニューロンについて呼吸, 発声, 嚥下, 咳時の活動変化 を解析した ${ }^{13)}$ ，麻酔下非動化モルモットを用い, これら の運動をモニターするために反回神経，上喉頭神経，腹筋 神経, 横隔神経活動を記録した。発声はPAGの電気刺激, 嚥下は上喉頭神経電気刺激, 咳は気管粘膜刺激あるいは反 回神経電気刺激で誘発した. BötC には呼息性ニューロン が多く存在し, rVRGには多くの吸息性ニューロンが存在 しており，これまで言われてきた呼吸ニューロンの局在様 式に一致していたが1)，その他のタイプのニューロンは吻 尾側に広く分布していた。また，これらの呼吸ニューロン は呼吸性活動だけでなく, 非呼吸性運動時にもそれぞれの タイプ毎に特有の活動パターンの変化を示した。 この結果 からrVRGから BötCの呼吸ニューロンが多機能性を有し ており，それぞれの非呼吸性運動に同期して呼吸神経ネッ トワーク構成を変化させることで様々な運動生成に貢献し ていることが確認された.

$$
\text { ま め め }
$$

喉頭科学に打ける電気生理学的なアプローチの基礎から 方法, それを用いた研究の一端を示した。喉頭運動制御义 カニズム解明は嚥下障害などの障害メカニズムの解明に必 須であるが，未だ不明な点が多い，今後のさらなる研究が 待たれるところである。

本内容は第 27 回日本喉頭科学会総会・学術講演会, 基 礎シンポジウム「喉を守る喉頭・気管領域の研究 UP TO DATE 〜若手喉頭科医による最新の知見」にて発表し た内容を改編したものである.

本稿において開示すべき利益相反はない.

\section{参 考 文 献}

1) Bianchi AL, Denavit-Saubié M, Champagnat J : Central control of breathing in mammals : neuronal 
circuitry, membrane properties, and neurotransmitters. Physiol Rev 75 : 1-45, 1995.

2) Feldman JL, Del Negro CA : Looking for inspiration: new perspectives on respiratory rhythm. Nature reviews. Neuroscience $7: 232-242,2006$.

3) Dutschmann M, Herbert H : The Kölliker-Fuse nucleus gates the postinspiratory phase of the respiratory cycle to control inspiratory off-switch and upper airway resistance in rat. Eur J Neurosci 24: 10711084, 2006.

4) Jürgens $U$ : The neural control of vocalization in mammals : a review. J Voice 23 : 1-10, 2009.

5) Sugiyama Y, Shiba K, Nakazawa K et al : Brainstem vocalization area in guinea pigs. Neurosci Res 66: 359-365, 2010.

6) Umezaki T, Matsuse T, Shin T : Medullary swallowing-related neurons in the anesthetized cat. Neuroreport 9 : 1793-1798, 1998.

7) Sugiyama Y, Shiba K, Nakazawa K et al : Axonal projections of medullary swallowing neurons in guinea pigs. J Comp Neurol 519 : 2193-2211, 2011.

8) Jean A : Brain stem control of swallowing: neuronal network and cellular mechanisms. Physiol Rev 81: 929-969, 2001.

9) Sugiyama Y, Shiba K, Mukudai S et al : Role of the retrotrapezoid nucleus/parafacial respiratory group in coughing and swallowing in guinea pigs. J Neurophysiol $114: 1792-1805,2015$.

10) Shannon R, Baekey DM, Morris KF et al : Functional connectivity among ventrolateral medullary respiratory neurones and responses during fictive cough in the cat. J Physiol 525 Pt 1 : 207-224, 2000.

11) Poliaček I, Stransky A, Szereda-Przestaszewska M et al : Cough and laryngeal muscle discharges in brainstem lesioned anaesthetized cats. Physiol Res 54 : 645-654, 2005.

12) Shannon R, Baekey DM, Morris KF et al : Ventrolateral medullary respiratory network and a model of cough motor pattern generation. J Appl Physiol (Bethesda, Md. : 1985) 84 : 2020-2035, 1998.

13) Sugiyama Y, Shiba K, Mukudai S et al : Activity of respiratory neurons in the rostral medulla during vocalization, swallowing, and coughing in guinea pigs. Neurosci Res $80:$ 17-31, 2014.

14) Korpáš J, Tomori $Z$ : Cough and Other Respiratory Reflexes. Basel, S. Karger, 1979

15) Saito Y, Ezure K, Tanaka I : Swallowing-related activities of respiratory and non-respiratory neurons in the nucleus of solitary tract in the rat. J Physiol 540 : 1047-1060, 2002.

16) Shiba K, Nakazawa K, Ono K et al : Multifunctional laryngeal premotor neurons: their activities during breathing, coughing, sneezing, and swallowing. J Neurosci 27 : 5156-5162, 2007.

17) Shiba K, Satoh I, Kobayashi N et al : Multifunctional laryngeal motoneurons: an intracellular study in the cat. J Neurosci 19 : 2717-2727, 1999

18) Broussard DL, Lynn RB, Wiedner EB et al. : Solitarial premotor neuron projections to the rat esophagus and pharynx: implications for control of swallowing. Gastroenterology 114: 1268-1275, 1998.

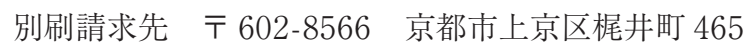
京都府立医科大学耳鼻咽喉科・頭頸部外科学教室 杉山庸一郎 